\title{
Ocean fronts construct spatial zonation in microfossil assemblages
}

\section{Dongyan Liu' ${ }^{1}$ (D) | Yanna Wang ${ }^{1}$ | Yueqi Wang ${ }^{2}$ | John K. Keesing ${ }^{3}$}

\author{
${ }^{1}$ State Key Laboratory of Estuarine and \\ Coastal Research, East China Normal \\ University, Shanghai, China \\ ${ }^{2}$ Key Laboratory of Coastal Zone \\ Environmental Processes and Ecological \\ Remediation, Yantai Institute of Coastal Zone \\ Research, Chinese Academy of Sciences, \\ Shandong, China \\ ${ }^{3} \mathrm{CSIRO}$ Oceans and Atmosphere \\ Research, Indian Ocean Marine Research \\ Centre, University of Western Australia \\ Oceans Institute, Crawley, Western Australia, \\ Australia
}

\section{Correspondence}

Dongyan Liu, State Key Laboratory of Estuarine and Coastal Research, East China Normal University, North Zhongshan Road 3663, Shanghai 200062, China.

Email: dyliu@sklec.ecnu.edu.cn

Funding Information

Natural Science Foundation of China, Grant/Award Number: 41376121; Chinese Academy of Sciences, Grant/Award Number: XDA11020405; Ministry of Science and Technology, Grant/Award Number: 2016YFE0133700.

\begin{abstract}
Aim: Integration of macroecology and palaeoecology is an important trend in understanding rapidly changing marine ecosystems. However, the spatial mismatch between these two data types has led to difficulties in interpretation, particularly for short-lived phytoplankton and their microfossils. Fronts are narrow transition zones between distinct water masses and play an essential role in partitioning phytoplankton assemblages in the ocean. Whether they also delimit microfossil assemblages deposited at the sea floor is unclear. We examined the correlation between quasi-stationary mesoscale fronts and the spatial distribution of microfossils (diatoms, dinoflagellates and silicoflagellates) in the Bohai, Yellow and East China Seas, to establish a causal link between microfossil assemblages and the factors controlling pelagic species assemblages on continental shelves.
\end{abstract}

Location: China.

Time period: 2003-2015.

Major taxa studied: Phytoplankton.

Methods: Front locations were determined using gradient analysis of monthly satellite sea surface temperature (SST) for 2003-2015. Microfossil assemblages were classified using two-way indicator species analysis of the relative abundance of 345 species collected from surface sediments at 126 sites. The relationships between frontal patterns and microfossil assemblages were evaluated by superimposing maps of front location, microfossil distribution and environmental features in the main water masses and by canonical correspondence analysis.

Results: Ten major fronts and four primary microfossil assemblages were identified. Analyses of the spatial patterns of fronts, microfossil assemblages, SST, salinity and nutrients revealed that the fronts partitioned the microfossils into assemblage types corresponding to the physicochemical features of the water masses.

Main conclusions: Microfossil species assemblages and their indicator species are separated by mesoscale fronts and are correlated with water properties. Producing base maps of microfossil assemblages in relationship to SST fronts enables examination of the importance of quasi-stationary mesoscale fronts in constructing microfossil patterns on continental shelves. The results displayed potential for the interpretation sediment core data and their integration with the macroecological context. 
Chinese seas, continental shelf, cyst, diatom, marine sediment, mesoscale fronts, palaeoecology, remote sensing, two-way indicator species analysis

\section{1 | INTRODUCTION}

Microfossils preserved in the marine sediments are the most important palaeoecological proxies for reconstructing short- and long-term environmental variations and biodiversity dynamics in the ocean (Smol \& Stoermer, 2010; Yasuhara, Tittensor, Hillebrand, \& Worm, 2017). Over the last decade, there has been growing interest in the integration of macroecology and palaeoecology for better understanding past, present and future changes in marine ecosystems (Finnegan et al., 2015; Fritz et al., 2013; Jablonski, Roy, \& Valentine, 2003; Yasuhara et al., 2017). However, the mismatch in spatio-temporal scales between macroecological and palaeoecological data collected in the dynamic ocean has led to significant uncertainty in statistical results (Fritz et al., 2013; Yasuhara et al., 2017). This is particularly true for passively drifting, short-lived phytoplankton and their microfossils on major shelves, where there are complex topographic and hydrodynamic characteristics. The influences driven by the interaction of coastal and oceanic environmental forces with seasonal reversal often generate distinct spatial heterogeneity on shelves. The difficulty becomes significant when studying the chronological record in sediment cores, and determining to what extent the results from a limited number of cores can be extrapolated spatially is a subject of much debate (Yasuhara et al., 2017). Thus, determining the factors controlling spatial correspondence between phytoplankton and their microfossils at various spatial scales is a key issue for better integration of the data between macroecological and palaeoecological investigations.

Ocean fronts are relatively narrow zones, representing large horizontal gradients of water properties (e.g., temperature and salinity) and separating distinct water masses in a broad area (Belkin, Cornillon, \& Sherman, 2009; Fedorov, 1986). They exist commonly in the world's oceans and exert a range of effects on pelagic ecosystems. The physical traits of fronts have an essential influence on the spatial patterns of pelagic ecosystems. Firstly, the physical actions from frontal convergence and along-front advection enable accumulation of nutrients and phytoplankton and, consequently, lead to high productivity at the front (e.g., Barton, Dutkiewicz, Flierl, Bragg, \& Follows, 2010; Belkin et al., 2009; Frontier, 1986; Olson et al., 1994; Venables, Meredith, Atkinson, \& Ward, 2012; Woodson \& Litvin, 2015). Secondly, there are sharp physical and chemical differences at the front (e.g., cross-frontal differences in temperature and salinity can be as large as $10-15^{\circ} \mathrm{C}$ and $2-3$ psu, respectively; Acha, Piola, Iribarne, \& Mianzan, 2015). These factors can cause the reorganization of phytoplankton assemblages from each side of the front and generate a distinct phytoplankton assemblage at the front. Thus, fronts have a function in partitioning the biogeographical boundaries of planktonic assemblages in the ocean, like the ecotone in terrestrial ecosystems
(Baltar, Currie, Stuck, Roosa, \& Morales, 2016; Kark, 2013; Longhurst, 2006; Margalef, 1997). Extensive evidence from satellite images and long-term in situ surveys indicates that the ecological features are relatively stable in the ocean, particularly for the major quasi-stationary or seasonally persistent fronts on shelves (Belkin et al., 2009; Frontier, 1986; Longhurst, 2006; Margalef, 1997). For example, the repetitive collection of continuous plankton records since 1948 shows that assemblages of diatoms and dinoflagellates in the North Atlantic Ocean present a clear and stable spatial pattern following the fronts in the Arctic, Atlantic and shelf regions (Longhurst, 2006). The biomass distribution of phytoplankton and zooplankton and their zonation in the Sea of Okhotsk, one of the most productive seas in the western North Pacific, is well matched to the frontal patterns (Belkin \& Cornillon, 2004; Pinchuk \& Paul, 2000). However, increased primary production and distinct assemblages at the front are not always present, depending on frontal types, their scale and other factors involved (e.g., light, grazing pressure).

Fronts have a three-dimensional structure, and their vertical extents vary from a few metres to $>1 \mathrm{~km}$, with some major fronts reaching the open ocean bottom at depths $>4 \mathrm{~km}$ (Belkin et al., 2009). Moreover, the frontal convergence can result in water masses sinking at rates of $10-100 \mathrm{~m} /$ day, compared with typical rates of 1-10 m/ day in the rest of the ocean (Ferrari, 2011). The secondary circulation produced in the vertical plane of the front can lead to the partitioning of particulate matter at each side of the front during deposition (Houghton, 1997, 2002 ). The vertical physical action at the front leaves fingerprints in the sediments. For example, Creutzberg (1985) compared sediment types on transect across a front off the Dutch coast in the North Sea and found that an extremely stable frontal boundary between tidally mixed and stratified waters had remained for $\geq 80$ years. Johannessen, Jansen, Flatøy, and Ravelo (1994) found that the distributions of planktonic foraminifera and carbon isotope in the surface sediments of the Greenland, Iceland and Norwegian Seas are highly associated with the surface water masses, the position of oceanic fronts and the sea ice extent. The Arctic Front is reflected by a clear isotopic gradient and by a strong switch from Neogloboquadrina pachyderma dominance to Globigerina quinqueloba dominance. Trimmer, Gowen, and Stewart (2003) measured the sediment characteristics across the western Irish Sea Front and found that the front clearly marked the boundaries of sediment types and pigment concentrations between western and eastern sides. Ren, Gersonde, Esper, and Sancetta (2014) discovered that the northern boundary of the diatom Fragilariopsis doliolus in the surface sediments occurred at the Subarctic Front. In previous studies, we also found that the spatial distribution of microfossils at the sea floor underwent a distinct change at a water depth of c. $50 \mathrm{~m}$ (Liu, Liu, Di, 

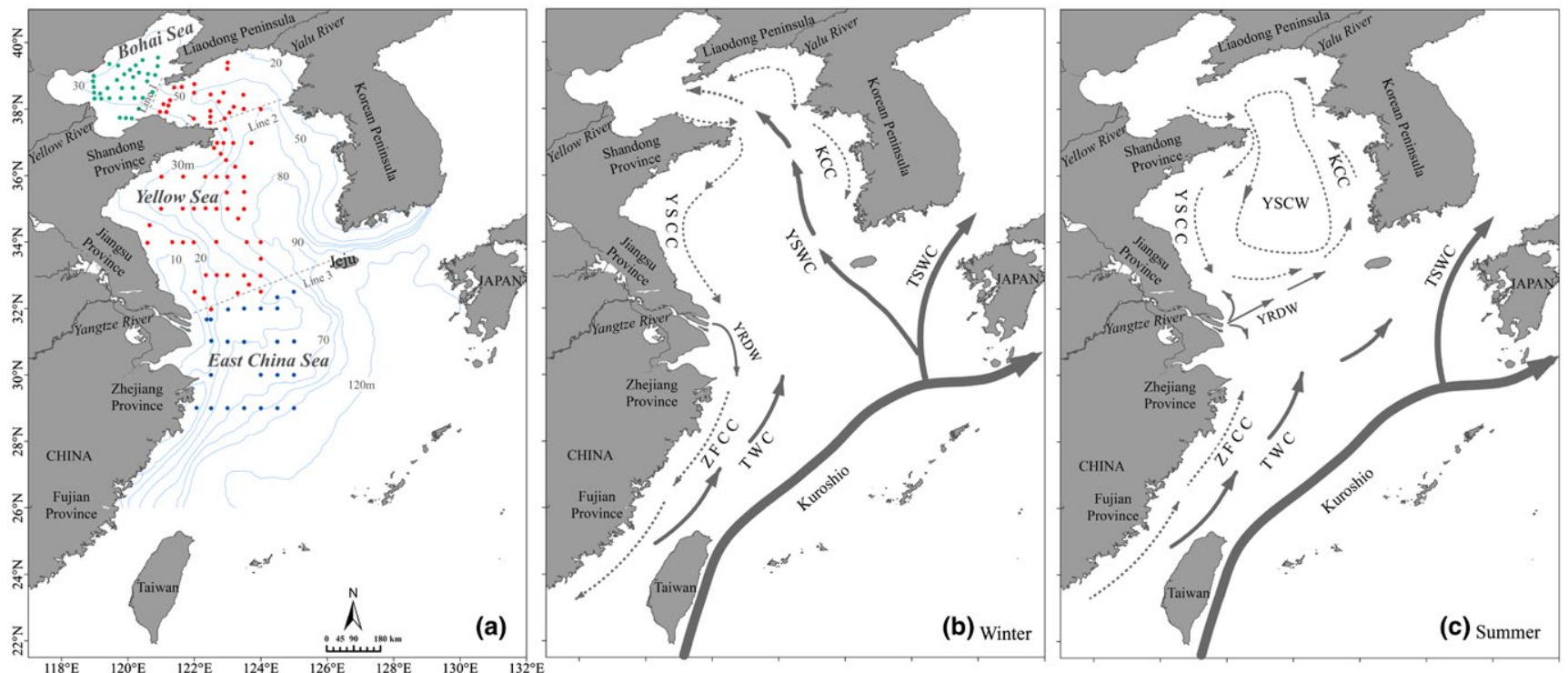

FIG URE 1 (a) Map of the Bohai, Yellow and East China Seas with isobaths and sampling sites (dashed lines showing the boundaries between seas; green, red and blue dots representing the sampling sites in each sea). (b,c) Schematic maps of major currents and water masses (b: winter circulation; c: summer circulation; CRDW = Changjiang (Yangtze) River Diluted Water; KCC = Korean Coastal Current; TSWC = Tsushima Warm Current; TWC = Taiwan Warm Current; YSCC = Yellow Sea Coastal Current; YSCW = Yellow Sea Cold Water mass; YSWC = Yellow Sea Warm Current; ZFCC = Zhejiang-Fujian Coastal Current). Redrawn from Su (1998) and Naimie et al. (2001)

Wang, \& Wang, 2015; Wang, Liu, Di, Shi, \& Wang, 2016), which is the position of major fronts that occur in the Bohai, Yellow and East China Seas (BYESs) (Hickox, Belkin, Cornillon, \& Shan, 2000).

These findings suggest that fronts could have a persistent shaping influence on the spatial distribution of microfossils at the seafloor and of the phytoplankton communities in the upper ocean. If so, they could lead to a spatial corresponding relationship between presentday phytoplankton distributions and the assemblage of their microfossils at frontal scales in shelves. To demonstrate the spatial link between fronts and microfossils further, we mapped major fronts in the BYESs using a gradient analysis, based on monthly climatological mean sea surface temperature (SST) images from MODIS/Aqua images from 2003-2015. Then, using a two-way indicator species analysis (TWINSPAN), we built a map of microfossil assemblage based on the taxa of 345 species (diatom fossils and dinoflagellate cysts) and their relative abundance collected from the surface sediments at 126 sites in the BYESs. Finally, according to an overlying comparison between microfossil assemblages and front positions in the BYESs, we determined the importance of fronts in constructing microfossil assemblages at the sea floor.

\section{2 | METHODS}

\section{1 | Study region}

The BYESs are major marginal shelves in the western Pacific Ocean and cover an area of c. $1.71 \times 10^{6} \mathrm{~km}^{2}$, surrounded by China, Korea and Japan (Figure 1a). In comparison, the Bohai Sea is the smallest and shallowest basin, with an area of $7.8 \times 10^{4} \mathrm{~km}^{2}$ and an average depth of $20 \mathrm{~m}$. The Yellow Sea is in the middle, connecting the Bohai and East China Seas, with an area of $3.8 \times 10^{5} \mathrm{~km}^{2}$ and an average depth of $44 \mathrm{~m}$; and the East China Sea is much larger and open to the Pacific Ocean (except for the partial barrier of Taiwan and Ryukyu Islands), with an area of $1.25 \times 10^{6} \mathrm{~km}^{2}$ and an average depth of $188 \mathrm{~m}$ (Su, 1998).

The dominant hydrodynamic processes in the BYESs are driven by the variations in tides, massive freshwater outflows, the seasonal reversal of the Asian monsoon, and incursions of the Kuroshio Current and its branches (Naimie, Blain, \& Lynch, 2001; Su, 1998). In winter (Figure $1 \mathrm{~b}$ ), a strong and cold northwesterly monsoon rapidly decreases the SST in the Bohai and Yellow Seas and, simultaneously, drives coastal waters southwards to form the Yellow Sea Coastal Current and Zhejiang-Fujian Coastal Current, which connects to the Yangtze River Diluted Water flowing southwards. In the south of the East China Sea, the warm and salty flows driven by the Kuroshio Current move northwards, branching and crossing the shelf into the Yellow Sea as the Yellow Sea Warm Current and extending northwards as far as the Bohai Sea. In summer (Figure 1c), the Yellow Sea Warm Current becomes weak, and the water mass produced by winter cooling and vertical mixing thus remains in the deep central Yellow Sea. This result in a basin-scale low-pressure system and cyclonic circulation called the Yellow Sea Cold Water Mass. Meanwhile, the wind stress of the south-easterly monsoon and enhanced freshwater discharge turn the Yangtze River Diluted Water eastward and separate the Yellow Sea Coastal Current and Zhejiang-Fujian Coastal Current.

The diverse water masses with distinct physical and chemical properties generate a high environmental heterogeneity in space. Owing to the supply of warm water from the Kuroshio Current and the latitudinal variation in solar radiation, the SST increases from the Bohai Sea to the Yellow Sea to the East China Sea, particularly in 
winter (Su, 1998). Numerous rivers from China and Korea, including two very large rivers (the Yellow River opening into the Bohai Sea and the Yangtze River flowing into the Yellow Sea), result in low salinity of the coastal water (generally $<31 \mathrm{psu}$ ), rich in nutrients (Chen, 2009). In contrast, shelf water is warm and saline (generally between 31 and 34 psu), with low nitrogen and silicate but phosphate rich, owing to the intrusion of the Kuroshio Current and its branches (Chen, 2009). The environmental pattern in space was also reflected in our two surveys (See Supporting Information Materials).

\subsection{Sea front detection}

Fronts along the BYESs were detected using gradient analysis (Belkin \& O'Reilly, 2009), based on the monthly climatological SST mean from MODIS/Aqua images of 2003-2015, between 24 and $41^{\circ} \mathrm{N}$, with a spatial resolution of $4 \mathrm{~km} \times 4 \mathrm{~km}$, downloaded from the U.S. National Aeronautics and Space Administration website (https://oceancolor. gsfc.nasa.gov; accessed in June 2016). The SST gradients were calculated in Matlab, using the gradient algorithm described by Belkin and O'Reilly (2009), and the monthly patterns of thermal fronts were produced according to the gradient magnitude. In the present study, mesoscale fronts are discussed and small-scale fronts excluded. The name of fronts in the BYESs followed the description by Hickox et al. (2000).

\section{3 | Microfossil assemblage analysis}

Diatoms and dinoflagellates are important groups among phytoplankton communities in temperate and polar seas and in the BYESs, and they contribute the conspicuous and well-preserved microfossils to marine sediments on continental shelves. In this study, the microfossil data used for assemblage analysis were obtained from previous studies (Liu et al., 2015; Shao et al., 2013; Wang et al., 2016), including the taxa of 285 diatoms, 58 dinoflagellate cysts and two silicoflagellates (Dictyocha fibula and Dictyocha messanensis). Microfossils were extracted from the top $2 \mathrm{~cm}$ of the surface sediment using box cores $\left(0.1 \mathrm{~m}^{2}\right)$ at 126 sites in the BYESs (Figure 1a) during two cruises in 2010-2011, and then species identification and enumeration were conducted using a microscope. According to previous studies in the BYESs, the range of modern sedimentation rates generally falls within $0.2-0.5 \mathrm{~cm} /$ year, but the sea adjacent to the Yangtze River is c. 0.6-3.0 cm/year owing to heavy sediment transport (Li, Gao, Jia, \& Zhao, 2002; Li, Hu, Dou, Zhao, \& Li, 2012). Thus, the estimated age in the top $2 \mathrm{~cm}$ of sediment cores is $c$. $<10$ years, which is likely to represent modern hydrological conditions. Likewise, the positions of fronts calculated from 13-year climatological data will match modern sedimentation processes in the BYESs.

TWINSPAN is a well-accepted method that uses indicative species to establish a hierarchical classification in a set of sample sites to assign and describe habitats (Hill, 1979; Hill \& Šmilauer, 2005). It is a two-way indicative species analysis that produces a tabular matrix of sample clusters showing which species are important indictors in defining each microfossil assemblage type. In the present study, 345 species and their relative abundance were analysed using TWINSPAN to measure their power as indicators, and this process was conducted in WinTWINS 2.3 software (Hill \& Šmilauer, 2005). The first step is species selection. Species with relative abundance $>0.5 \%$ were selected for statistical analysis to minimize the impact of rare species on the result of significance tests. The selected data were processed in WinTWINS 2.3 to obtain an ordered two-way table. The levels of species relative abundance used to define the crude scale are termed "pseudospecies cut levels" in TWINSPAN; the defaults were set as 0\%, 2\%, 5\%, 10\% and $20 \%$ in WinTWINS 2.3. We also compared the results at cut-off levels of $0 \%, 3 \%, 6 \%, 15 \%$ and $30 \%$ to ensure that the output was not overly sensitive to small changes in cut-off levels. One hundred and twenty-six sites were classified using a hierarchical algorithm; they were first divided into two subsets according to their sign on the first axis of a correspondence analysis ordination, whereby each subset was divided into two smaller subsets by repeating the same procedure. At each step, each species received an attribute describing its preference for one or the other side of the partition. These attributes were used to establish a refined site ordination and assemblage classification.

\subsection{Correlation between fronts and microfossil assemblages}

An overlying comparison between frontal and microfossil assemblage maps was designed to explore the role of the fronts in determining microfossil assemblages at the sea floor. Briefly, the major quasi-stationary fronts in the BYESs were chosen to form an integrated base map, and then 126 sites charactering different microfossil assemblages were superimposed on the base map. These maps were constructed using ArcGIS 10.2 (ESRI, Redlands, CA, USA) software. The correlations between the indicative species weighted by TWINSPAN and the environmental factors (SST, salinity and nutrients in winter and spring during the peak period of the fronts) corresponding to the main water masses were analysed using a canonical correspondence analysis (CCA) in the program CANOCO version 4.5 (ter Braak, 1986; ter Braak \& Smilauer, 2002). The environmental data used for CCA were collected in the BYESs during research voyages supported by the National Natural Science Foundation of China, and these data have not been published previously; therefore, we have supplied the methods of data collection and the spatial patterns of SST, salinity and nutrients as Supporting Information in this study.

\section{3 | RESULTS}

\subsection{Fronts in the BYESs}

The gradient analysis of SST generated 10 major quasi-stationary fronts (Figure 2a), including the Kuroshio Shelf Front (front 1), eight coastal fronts (fronts 2-5 in China: Zhejiang-Fujian, Jiangsu, Shandong, Bohai Strait; and fronts 6-9 in South Korea: Seohan Bay, Kyunggi Bay, Western Cheju, Eastern Cheju) and Yangtze Bank Ring Front (front 10). In a spatial comparison, the frontal types in the East China Sea are more diverse than those found in the Bohai and Yellow 

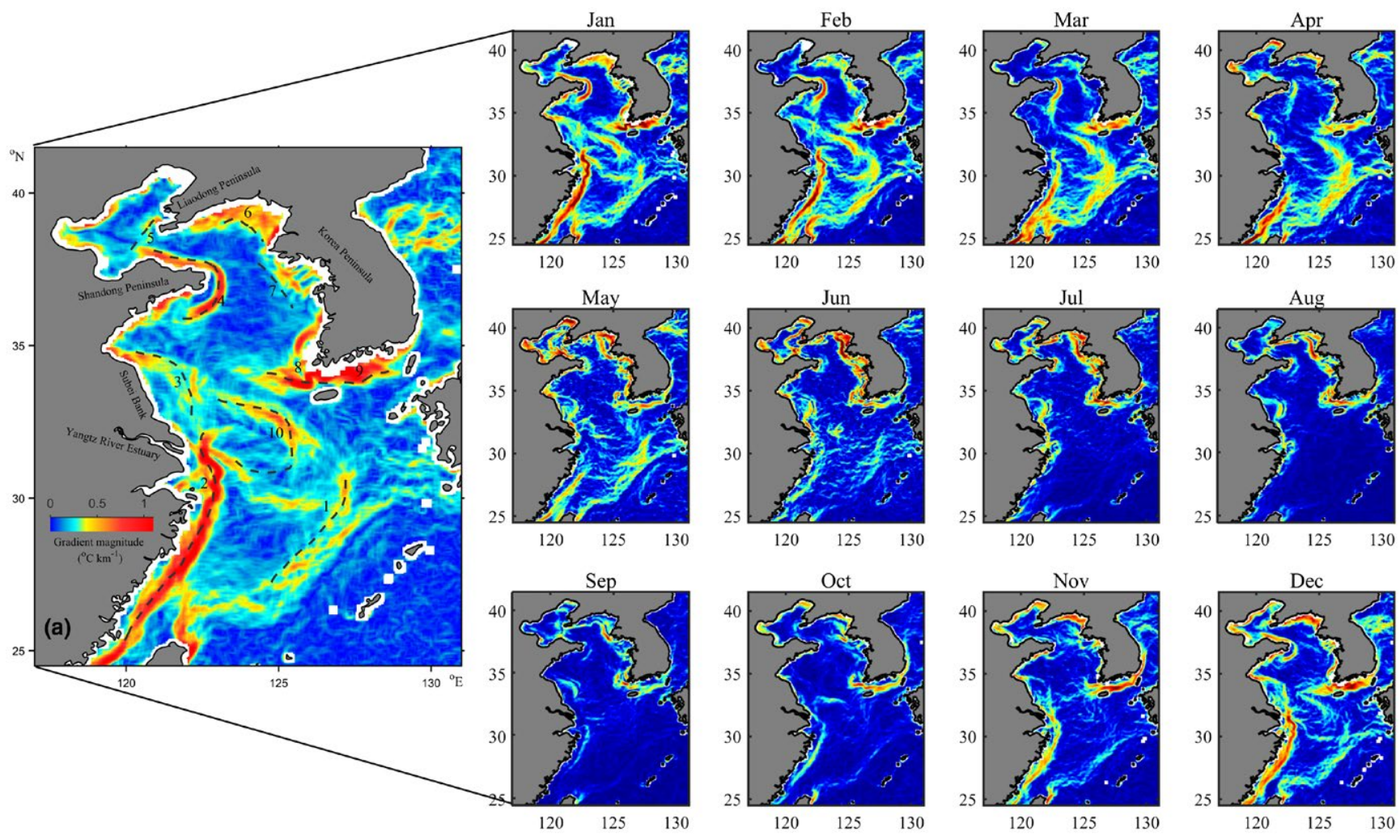

(b)
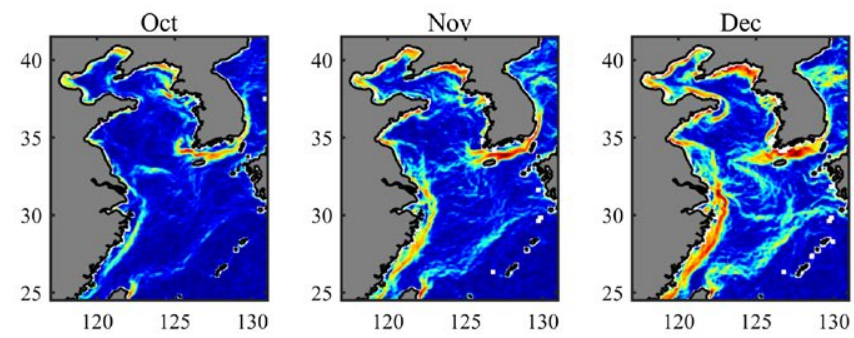

Gradient magnitude $\left({ }^{\circ} \mathrm{C} \mathrm{km}^{-1}\right)$

$\begin{array}{llllll}0 & 0.2 & 0.4 & 0.6 & 0.8\end{array}$

FIGURE 2 (a) An integrated frontal map of 10 major fronts in the Bohai, Yellow and East China Seas (BYESs; $1=$ Kuroshio Shelf Front; 2 = Zhejiang-Fujian Front; 3 = Jiangsu Front; 4 = Shandong Front; 5 = Bohai Strait Front; 6 = Seohan Bay Front; 7 = Kyunggi Bay Front; 8 = Western Cheju Front; 9 = Eastern Cheju Front; 10 = Yangtze River Ring Front). (b) Monthly variations of the 10 major fronts in the BYESs [Colour figure can be viewed at wileyonlinelibrary.com]

Seas, and the Yellow River plume plays a lesser role in the Bohai Sea than does the Yangtze River plume in the East China Sea. Most fronts present a seasonally persistent pattern (Figure $2 b$ ), emerging from the autumn (October-November), peaking in the winter-spring (December-May) and fading in the summer (June-September). Some fronts (e.g., Kuroshio Shelf Front, Yangtze Bank Ring Front) display a characteristic discontinuity in space and time, indicating the complicated interactions of various water masses under the impact of topography, seasonal monsoon and current flow patterns.

\section{2 | Geographical pattern of microfossil assemblages in the BYESs}

TWINSPAN grouped the 126 sites into 4 primary microfossil assemblages (Figure $3 a$ ), and varying the cut-off levels in the TWINSPAN analyses made negligible difference to the output, with only a few samples shifting between sub-assemblages. We named them as the Coastal Assemblage (CA), Yellow Sea Shelf Assemblage (YSSA), Yangtze River Plume Assemblage (YRPA) and East China Sea Shelf Assemblage (ECSSA), according to their geographical locations (Figure 3b). Each primary assemblage has two to five sub-assemblages (subsets), and their indicative species are presented in Table 1.

The geographical relationship between frontal positions and microfossil assemblages is shown in Figure $3 \mathrm{~b}$. The CA, including three subsets, is mainly constrained landside by coastal fronts 3, 4 and 5 into the Bohai, Shandong and Jiangsu coastal waters (Figure 3b; red and pink dots). The YSSA, with five subsets, mainly distributes in the central Yellow Sea and frontal edges (coastal fronts 3, 4, 5 and 6 and the Yangtze Bank Ring Front 10), except for a few sites distributed between Shandong and Jiangsu coasts, where there is a discontinuity between fronts 3 and 4 (Figure 3b; blue squares). The YRPA has two subsets (Figure 3a), and their distribution dominates in the region surrounded by the Yangtze Bank Ring Front (10), but it displays an extension southwards and northwards (Figure $3 \mathrm{~b}$; green asterisks), following the pathway of Yangtze River Diluted Water that can expand seasonally into Jiangsu and Zhejiang coastal waters (Figure 1b). The ECSSA, including four subsets, dominates in the region surrounded by fronts 1, 2 and 10, but also extends northwards, mixing with the YRPA (Figure 3b; purple triangles). At each front (except for front 2), the ecotone of adjacent assemblages is evident.

\subsection{The correlation between indicative species and environmental factors}

Two or three representative species in each microfossil assemblage weighted by TWINSPAN (Table 1) were selected to verify their indicative role. The spatial distribution of species in proportional abundance 


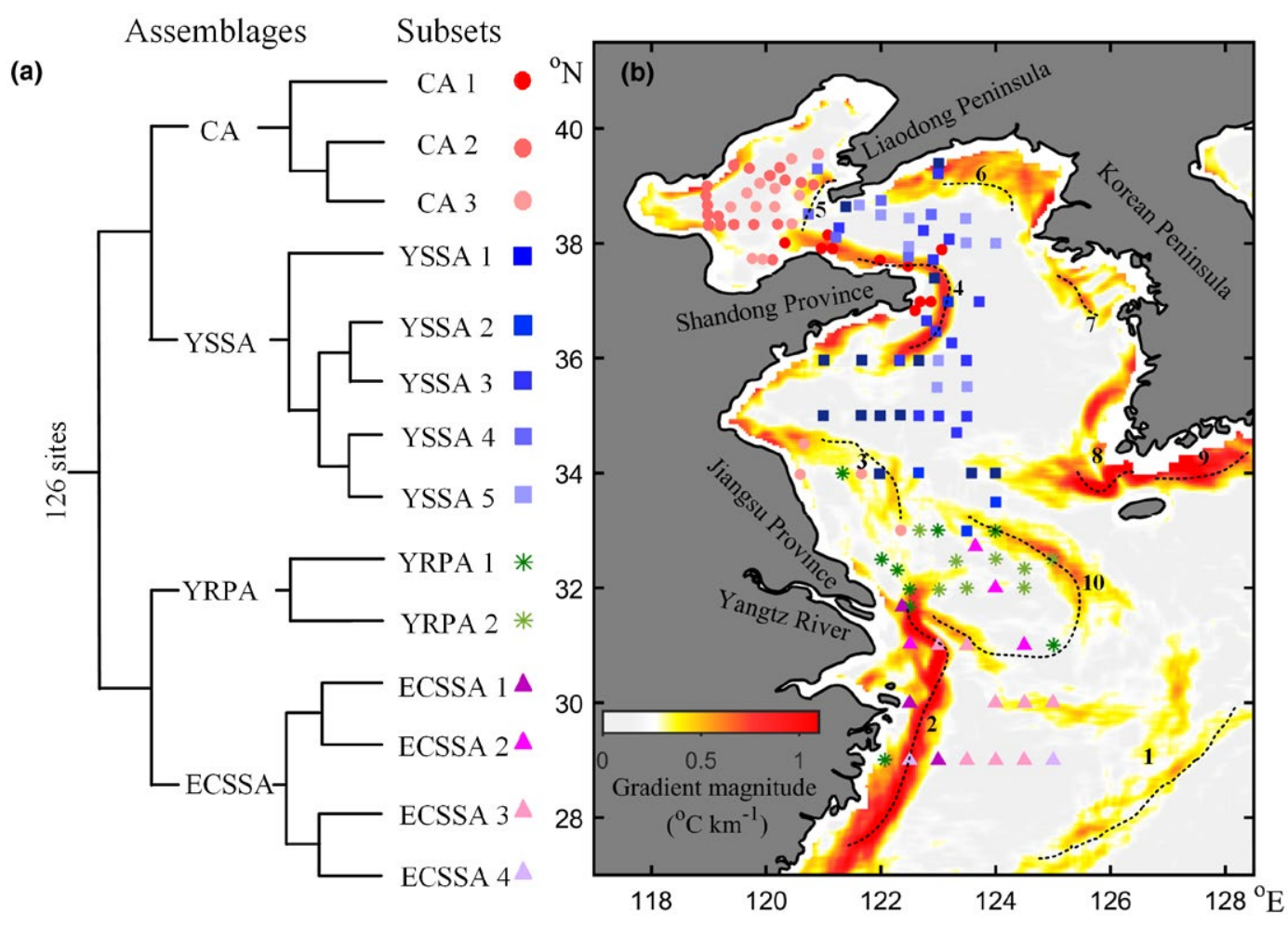

FIGURE 3 (a) Classification of microfossil assemblages from a two-way indicator species analysis (TWINSPAN; CA = Coastal Assemblage; ECSSA = East China Sea Shelf Assemblage; YRPA = Yangtze River Plume Assemblage; YSSA = Yellow Sea Shelf Assemblage). (b) Geographical map of microfossil assemblages coupled with front patterns [Colour figure can be viewed at wileyonlinelibrary.com]

mainly followed the pattern of frontal division (Figure 4). Owing to the interruption of Yangtze River Diluted Water, species from $34^{\circ} \mathrm{N}$ northwards displayed significant differences. Meanwhile, the geographical connection between the seas can be seen from the indicative species (e.g., Trachyneis antillarum and Trachyneis aspera showed a link between the Yellow and East China Seas along the pathway of the Yellow Sea Warm Current; Coscinodiscus curvatulus and Actinocyclus ehrenbergii displayed a geographical connection between the Bohai and Yellow Seas).

The result of the CCA further explained the ecological preferences of species in each assemblage (Figure 5). The species near to the Yangtze River Estuary (7. Actinoptychus splendens, 8. Protoperidinium compressum, 10. Coscinodiscus jonesianus, 11. Protoperidinium claudicans) were positively correlated with nutrients, whereas species dominating in the Yellow Sea Warm Current and Kuroshio Current (4. T. antillarum, 5. T. aspera, 6. C. curvatulus, 9. Coscinodiscus nodulifer) showed a positive correlation with SST and salinity. In contrast, species from CA (A. ehrenbergii, Gonyaulax spinifera and Polykrikos schwartzii) mainly dominated in coastal regions of the Bohai and Yellow Seas, having a negative correlation with SST and salinity, matching lower salinity and colder weather in winter and spring.

\section{4 | DISCUSSION}

Superimposition of frontal patterns and microfossil assemblages reveals the important role of fronts in partitioning microfossil assemblages in the BYESs. Although a cross-distribution (commonality of some microfossils) appears between YRPA and ECSSA, most are distinct biotic provinces (Figure $3 b$ ). The spatial distribution of phytoplankton communities is highly associated with physical and chemical properties of individual water masses. The mosaics of water masses with different properties generally characterize the shelves, and major fronts on the shelves typically form between distinct water masses with sharp gradients in salinity and temperature (Mann \& Lazier, 2006). Thus, we discuss the physical and chemical features of four dominant water masses (Figure 1b,c: Kuroshio Current, Taiwan Warm Current, Yellow Sea Warm Current and Coastal Current) forcing the formation of mesoscale fronts in the BYESs, to gain a better understanding of the spatial links between frontal and microfossil assemblage patterns.

The coastal fronts in the BYESs are typical tidal fronts, generated by sloping topography and tidal mixing (Hickox et al., 2000). The physical traits of tidal fronts are not fully understood, owing to the frontal scales and positions (Pedersen, 1994). However, Chen and Beardsley (1998) and Houghton (2002) gave some explanations, which provide a partial understanding of the physical mechanisms that tidal fronts exert on sedimentation. Strong tidal mixing in shallow waters leads to well-mixed water masses, and the water masses stratify as the action of tidal mixing weakens in deep waters (Figure 6a). The significant gradient force penetrating the front leads to considerable baroclinic pressure, which stimulates convergence at the sea floor and secondary circulation in the vertical plane, leading 
TAB LE 1 Indicator species weighted by a two-way indicator species analysis in each microfossil assemblage and its subsets

$\begin{array}{lll}\text { Assemblage Subset } & \text { Diatoms } \\ \text { CA } & \mathrm{CA}_{1} & \\ & \\ \mathrm{CA}_{2} & \begin{array}{l}\text { Actinocyclus ehrenbergii var. tenella } \\ \text { Diploneis bombus } \\ \end{array} & \begin{array}{l}\text { Diploneis schmidtii } \\ \text { Pleurosigma normanii } \\ \end{array} \\ & \text { Podosira stelliger } \\ \mathrm{CA}_{3} & \text { P. stelliger }\end{array}$

YSSA

$\mathrm{YSSA}_{1}$

Actinocyclus ehrenbergii var. Ralfssi

A. ehrenbergii var. tenella

Actinocyclus subtilis

Cyclotella striata

Trachyneis antillarum

Trachyneis aspera

$\mathrm{YSSA}_{2} \quad$ Coscinodiscus curvatulus

C. curvatulus var. minor

T. antillarum

$\mathrm{YSSA}_{3} \quad$ C. curvatulus

C. curvatulus var. minor

T. antillarum

$\mathrm{YSSA}_{4} \quad$ Delphineis surirella

Thalassiosira excentrica

T. antillarum

$\mathrm{YSSA}_{5}$

D. surirella

D. schmidtii

T. antillarum

YRPA

YRPA

Actinoptychus splendens

A. ehrenbergii var. Ralfsii

Coscinodiscus jonesianus

Coscinodiscus kützingii

Nitzschia subtilis

Tryblioptychus cocconeiformis

$\mathrm{YRPA}_{2} \quad$ Actinoptychus annulatus

A. splendens

A. ehrenbergii var. Ralfsii

C. jonesianus

N. subtilis

T. cocconeiformis

\section{Dinoflagellate cysts}

Gonyaulax spinifera

Polykrikos schwartzii

Spiniferites bentori var. truncata

Spiniferites delicatus

G. spinifera

P. schwartzii

Protoperidinium latissimum

S. bentori var. truncata

S. delicatus

G. spinifera

P. schwartzi

S. bentori var. truncata

\section{S. delicatus}

Protoperidinium oblongum

Protoperidinium pentagonum

Pyrophacus steinii

Gonyaulax scrippsae

P. steinii

Polykrikos kofoidii

Protoperidinium compressum

P. pentagonum

\section{P. kofoidii}

P. compressum

P. pentagonum 
TABLE 1 (Continued)

\begin{tabular}{|c|c|c|c|}
\hline Assemblage & Subset & Diatoms & Dinoflagellate cysts \\
\hline \multirow[t]{33}{*}{ ECSSA } & ECSSA $_{1}$ & A. annulatus & P. kofoidii \\
\hline & & A. splendens & P. compressum \\
\hline & & C. jonesianus & P. pentagonum \\
\hline & & Cymatotheca weissflogii & \\
\hline & & N. subtilis & \\
\hline & & Surirella fastuosa & \\
\hline & & T. excentrica & \\
\hline & & Thalassiothrix delicatula & \\
\hline & & T. cocconeiformis & \\
\hline & $\mathrm{ECSSA}_{2}$ & A. annulatus & P. kofoidii \\
\hline & & A. splendens & P. compressum \\
\hline & & C. jonesianus & P. pentagonum \\
\hline & & C. weissflogii & \\
\hline & & N. subtilis & \\
\hline & & S. fastuosa & \\
\hline & & T. excentrica & \\
\hline & & T. delicatula & \\
\hline & & T. cocconeiformis & \\
\hline & $\mathrm{ECSSA}_{3}$ & C. jonesianus & P. kofoidii \\
\hline & & C. nodulifer & P. compressum \\
\hline & & & P. claudicans \\
\hline & & N. subtilis & P. pentagonum \\
\hline & & S. fastuosa & \\
\hline & & T. excentrica & \\
\hline & & T. delicatula & \\
\hline & & T. cocconeiformis & \\
\hline & $\mathrm{ECSSA}_{4}$ & C. jonesianus & P. kofoidii \\
\hline & & C. nodulifer & P. compressum \\
\hline & & N. subtilis & P. claudicans \\
\hline & & S. fastuosa & \\
\hline & & T. excentrica & \\
\hline & & T. delicatula & P. pentagonum \\
\hline & & T. cocconeiformis & \\
\hline
\end{tabular}

Note. $\mathrm{CA}=$ Coastal Assemblage; ECSSA $=$ East China Sea Shelf Assemblage; YRPA = Yangtze River Plume Assemblage; YSSA = Yellow Sea Shelf Assemblage.

to the partition of phytoplankton debris and other small particles (Figure 6a). The result of this physical separation has been observed in the sediments. As we mentioned before, Creutzberg (1985) discovered this phenomenon in the sediments across a front off the Dutch coast in the North Sea. Zang et al. (2015) measured the spatial variations of suspended sediment along the Shandong Front (Figure 2a; front 4) and found that it can significantly slow down the transport of suspended sediment, leading to more rapid deposition on the coastal side of the front and generating different sediment types on each side of the front.

The intensity of tidal mixing around the Chinese and Korean coasts and the intrusion of the Yellow Sea Warm Current greatly determine the probability of coastal fronts (Huang, Zhang, \& Zhou, 2010; Park $\&$ Chu, 2006). In winter, the warmer, saltier and nutrient-poor Yellow Sea Warm Current moves northwards and interacts with colder, less saline and nutrient-rich coastal waters to form distinct coastal fronts (Figures 1 and 2b). Notably, there is a discontinuity between fronts 3 and 4 (Figure 2a), owing to the influence of the westward pathway of the Yellow Sea Warm Current in winter and spring (Park \& Chu, 2006). In summer, the huge Yellow Sea Cold Water Mass in the central Yellow Sea can result in a subsurface front between coastal and offshore waters (Park \& Chu, 2006); therefore, the surface fronts seem much weaker than they are in winter (Figure 2b). Thus, surface and subsurface fronts existing in the Yellow Sea consequently lead to the 


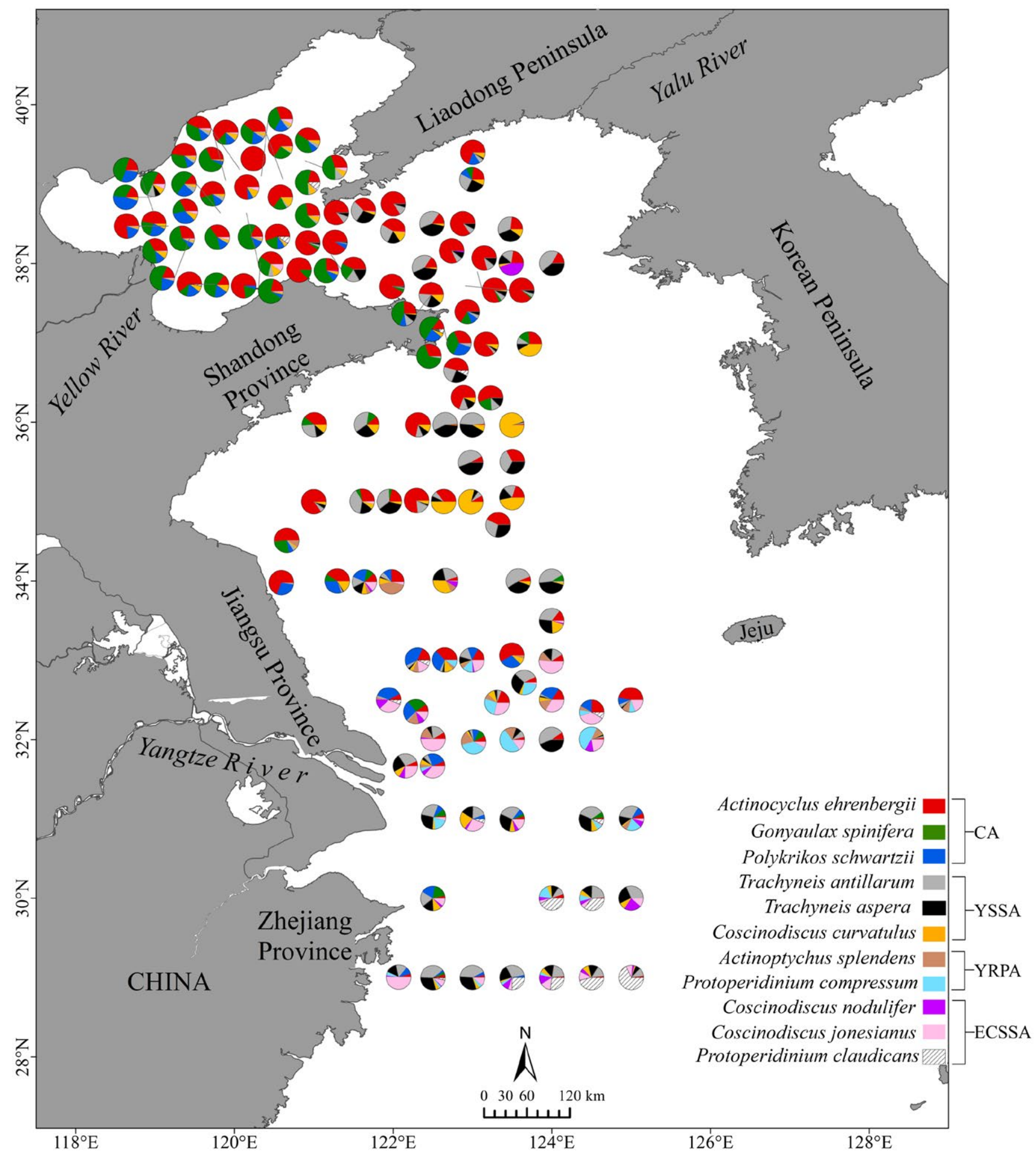

FIGURE 4 The spatial distribution of representative species in each microfossil assemblage weighted by a two-way indicator species analysis (TWINSPAN) [Colour figure can be viewed at wileyonlinelibrary.com]

partitioning of phytoplankton deposition on each side of the coastal fronts and generate two types of microfossil assemblages (CA and YSSA; see the pattern in Figure 3). Species with lower salinity and temperature preference dominate in the CA. For example, A. ehrenbergii, a typical brackish-water-favouring species that is abundant in colder waters (Hood, Abbott, Huyer, \& Kosro, 1990; Rijstenbil, 1987), is mainly distributed in the Bohai and northern Yellow Seas (Figure 5). In contrast, indicator species in the YSSA display a positive correlation with SST and salinity (Figure 5); for instance, T. antillarum, distributing on the pathway of the Yellow Sea Warm Current and Kuroshio Current, was recorded as a warm water species related to the Kuroshio Current in the Japan Sea (Koizumi, 1989). 


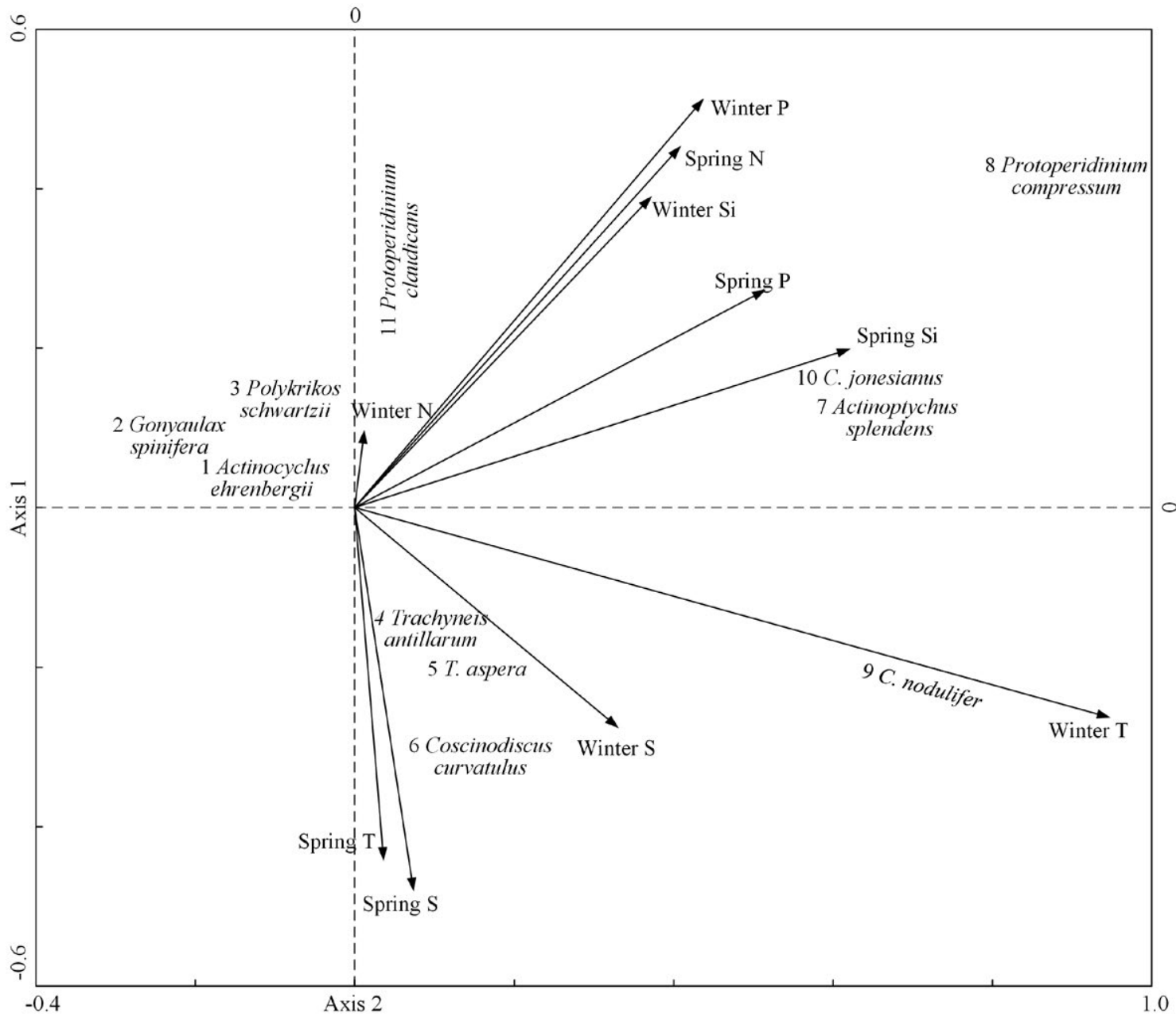

FIGURE 5 Canonical correspondence analysis of representative species (CA: 1 = Actinocyclus ehrenbergii, $2=$ Gonyaulax spinifera and 3 = Polykrikosschwartzii; YSSA:4 = Trachyneisantillarum, 5 = Trachyneisaspera and 6 = Coscinodiscuscurvatulus; YRPA:7 = Actinoptychussplendens and 8 = Protoperidinium compressum; ECSSA: $9=$ Coscinodiscus nodulifer, $10=$ Coscinodiscus jonesianus and $11=$ Protoperidinium claudicans) and environmental factors $(\mathrm{N}=$ nitrogen; $\mathrm{P}=$ phosphorus; $\mathrm{S}=$ salinity; $\mathrm{Si}=$ silicate; $\mathrm{T}=$ temperature $)$

(a) Tidal front

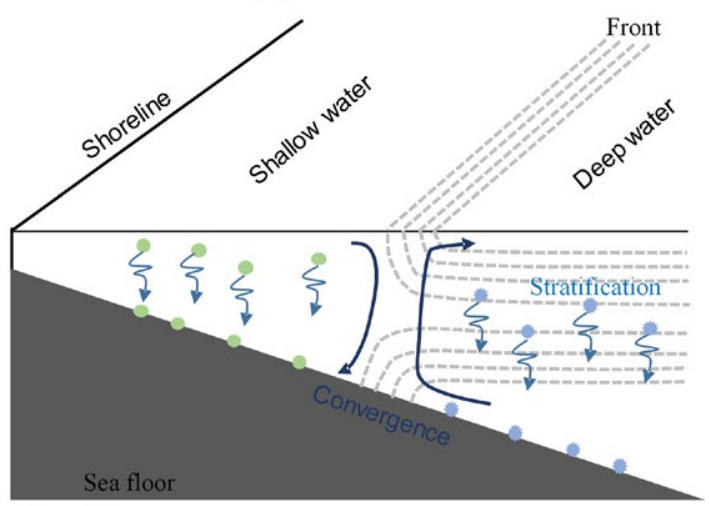

\{and $\{s$

(b) Shelf-break front

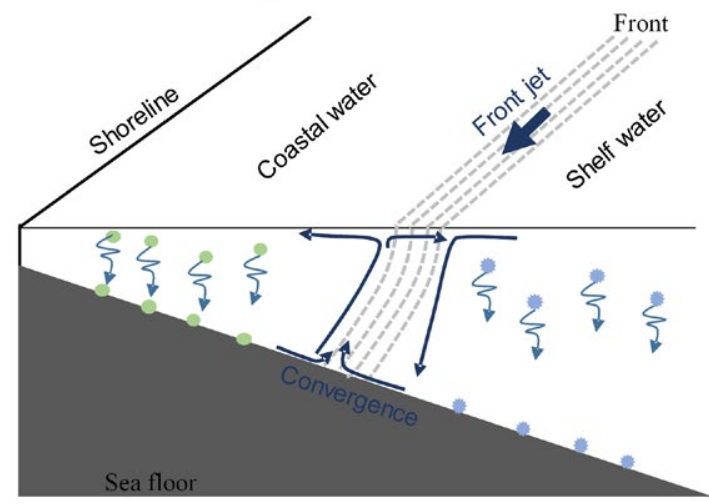

Front 
In the sea adjacent to the Yangtze River Estuary and East China Sea, frontal patterns and microfossil assemblages are more diverse (Figures 2 and 3). There is a complicated hydrodynamic process in this region, under the interactions of the Yangtze River Diluted Water, Coastal Current, Kuroshio Current and Taiwan Current. In the southern East China Sea, the warm and saline Kuroshio Current invades towards the shelf north of Taiwan to form a constant shelf-break front (Figure 2a; front 1, Kuroshio Shelf Front). The shelf front not only can form a high-density barrier in the horizontal plane but also can produce secondary circulation (upwelling and downwelling) in the vertical plane (Chapman \& Lentz, 1994; Houghton, 1997). The secondary circulation can separate the microfossil deposition on each side of the front (Figure 6b). Meanwhile, the Taiwan Warm Current from the western side of Taiwan flows northwards all year (Figure 1b,c) and meets the Zhejiang-Fujian Coastal Current to form the ZhejiangFujian Front (Figure 2a). These fronts circle a large habitat, with warm, saline and phosphate-rich water properties (Chen, 2009). Thus, indicative species from the East China Sea Shelf Assemblage (ECSSA) show a positive correlation with SST and salinity (Figure 5; e.g., C. nodulifer is a typical warm and saline species and is used to indicate coastal upwelling; Koizumi, 1989; Schrader \& Sorknes, 1991).

In the northern East China Sea, a huge freshwater discharge from the Yangtze River is maintained by tidal rectification that results in a clockwise current and the formation of a closed quasi-circular Yangtze Bank Ring Front around the shoal (Belkin et al., 2009; Hickox et al., 2000). It not only interrupts the spatial connection between the Yellow Sea and the East China Sea but also creates a large Yangtze River Plume Assemblage (YRPA) habitat with low salinity and rich nutrients (Figure 3). Seasonal reversal of the Asian monsoon can modify plume dynamics. In winter and spring (December-March), strong northwestern monsoons can push part of the Yangtze River Diluted Water southwards and bring species into the Zhejiang-Fujian coastal current. In summer (June-September), the southeastern monsoon turns part of the Yangtze River Diluted Water northwards and brings species into the Jiangsu Coastal Current (Wu, Shen, Zhu, Zhang, \& Li, 2014). These dynamics explain why the YRPA can extend to the adjacent Coastal Currents (Figure 3b).

Several cases indicated that fronts exert mixing effects on the adjacent populations (Acha et al., 2015). In this study, the cross-distribution between adjacent microfossil assemblages occurred at the frontal positions, particularly between YRPA and ECSSA (Figure 4b). The cross-front mixing or transport depends on a variety of mechanisms; for instance, the eddies formed owing to the front instability that occurs when the along-front flow is vigorous (strong gradient) can make a significant contribution to cross-front transport (Ferrari \& Nikurashin, 2010). Yuan, Qiao, and Su (2005) observed clear crossshelf penetrating fronts with a distance usually $>50 \mathrm{~km}$ in the East China Sea and attributed the cause to seasonal reversal, which significantly weakens the interactions among water masses by pushing the Taiwan Warm Current and Kuroshio Current further offshore. Theoretically, cross-shelf penetrating fronts can assist the species of ECSSA to enter the Yangtze Bank Ring Front, forming interlaced microfossil assemblages.
In the oceanic space-time continuum of processes, fronts are typically places where physical and biological scales tend to coincide (Sournia, 1994). They have been given full consideration in pelagic biogeographical studies, even if some of their effects are still poorly understood (Acha et al., 2015; Baltar et al., 2016; Barton et al., 2010; Longhurst, 2006; Sournia, 1994). However, the role of fronts in partitioning the microfossil assemblages at the sea floor has not been given enough attention, although the signal retained in the sediments has been conveyed in case studies (Abelmann, Gersonde, Cortese, Kuhn, \& Smetacek, 2006; Creutzberg, 1985; Johannessen et al., 1994; Ren et al., 2014; Trimmer et al., 2003). Here, we provided a simple method, producing a base map of microfossil assemblages in relationship to SST fronts derived from remote sensing data, to discover their tight spatial linkage at mesoscales. Major quasi-stationary or seasonally persistent fronts commonly exist on shelves (e.g., the East and West Bering Seas, the Sea of Okhotsk, the North Sea, the East and West Greenland Shelves), and they all show positive correlation with high chlorophyll $a$ concentrations (Belkin et al., 2009). Reliable data sets of diatom species composition in surface sediments have been well established in some shelves, such as the North Atlantic Ocean (Koç Karpuz \& Schrader, 1990), Southern Ocean (Zielinski \& Gersonde, 1997) and North Pacific (Ren et al., 2014). Therefore, our methodology is likely to be widely applicable among the world's continental shelf seas to examine the correlation between microfossil assemblages and SST fronts. The results will help us to weigh the importance of mesoscale fronts in constructing microfossil patterns and gain a better understanding of why microfossil assemblages differ from one region to another at the sea floor.

The estimation of palaeoenvironmental variations from microfossils has become an important tool for understanding modern climate change and species geographical distribution (Finnegan et al., 2015; Fritz et al., 2013). The dynamics of mesoscale fronts are related to the variation of sea temperature. If the sedimentary range of a given species (or group of species) is regularly restricted at the front, it could become an independent proxy in the sediment core for reconstructing mesoscale front positions in the past. For example, the glacial northwards shift of the subtropical front agrees with records from foraminiferal and coccolithophore assemblages in this region (Bard \& Rickaby, 2009). The Antarctic Polar Front migrated c. $6^{\circ}$ of latitude further to the south during the Pliocene warm interval, leaving a fingerprint in the relative percentages of diatom taxa (Barron, 1996). Therefore, fronts should be high-priority sites for palaeoecological investigation.

\section{ACKNOWLEDGMENTS}

We appreciated the scientific comments from physical oceanographers Dr Dennis J. McGillicuddy at Woods Hole Oceanography Institute, USA and Dr Jilan Su at State Oceanic Administration of China, China. The study was funded by the Natural Science Foundation of China (41376121), the Strategic Priority Research 
Program of the Chinese Academy of Sciences (XDA11020405) and Project 2016 YFE0133700 from the Ministry of Science and Technology, China. The authors declare no conflicts of interest.

\section{DATA ACCESSIBILITY}

All topographic and environmental GIS layers, the habitat suitability model and BTM results generated for this study are available as raster grids from the Pangaea database: https://doi.pangaea.de/10.1594/ PANGAEA.808540.

\section{ORCID}

Dongyan Liu (iD http://orcid.org/0000-0003-3606-9846

\section{REFERENCES}

Abelmann, A., Gersonde, R., Cortese, G., Kuhn, G., \& Smetacek, V. (2006). Extensive phytoplankton blooms in the Atlantic sector of the glacial. Southern Ocean. Paleoceanography and Paleoclimatology, 21, PA1013. https://doi.org/10.1029/2005PA001199

Acha, E. M., Piola, A., Iribarne, O., \& Mianzan, H. (2015). Ecological processes at marine fronts: Oases in the ocean. London: Springer.

Baltar, F., Currie, K., Stuck, E., Roosa, S., \& Morales, S. E. (2016). Oceanic fronts: Transition zones for bacterioplankton community composition. Environmental Microbiology Reports, 8, 132-138. https://doi. org/10.1111/1758-2229.12362

Bard, E., \& Rickaby, R. E. M. (2009). Migration of the subtropical front as a modulator of glacial climate. Nature, 460, 380-384. https://doi. org/10.1038/nature08189

Barron,J.A. (1996). Diatomconstraintsontheposition of the Antarctic Polar Front in the middle part of the Pliocene. Marine Micropaleontology, 27, 195-213. https://doi.org/10.1016/0377-8398(95)00060-7

Barton, A. D., Dutkiewicz, S., Flierl, G., Bragg, J., \& Follows, M. J. (2010). Patterns of diversity in marine phytoplankton. Science, 327, 15091511. https://doi.org/10.1126/science.1184961

Belkin, I. M., \& Cornillon, P. C. (2004). Surface thermal fronts of the Okhotsk Sea. Pacific Oceanography, 2, 619.

Belkin, I. M., Cornillon, P. C., \& Sherman, K. (2009). Fronts in large marine ecosystems. Progress in Oceanography, 81, 223-236. https://doi. org/10.1016/j.pocean.2009.04.015

Belkin, I. M., \& O'Reilly, J. E. (2009). An algorithm for oceanic front detection inchlorophyllandSST satellite imagery. Journal of Marine Systems, 78, 319-326. https://doi.org/10.1016/j.jmarsys.2008.11.018

Chapman, D. C., \& Lentz, S. J. (1994). Trapping of a coastal density front by the bottom boundary layer. Journal of Physical Oceanography, 24, 1464-1479. https://doi.org/10.1175/1520-0485(1994)024 aabbb1464:TOACDFaaabb2.0.CO;2

Chen, C. T. A. (2009). Chemical and physical fronts in the Bohai, Yellow and East China Seas. Journal of Marine Systems, 78, 394-410. https://doi. org/10.1016/j.jmarsys.2008.11.016

Chen, C., \& Beardsley, R. C. (1998). Tidal missing and cross-frontal particle exchange over a finite amplitude asymmetric bank: A model study with application to Georges Bank. Journal of Marine Research, 22, 2061-2074.

Creutzberg, F. A. (1985). Persistent chlorophyll a maximum coinciding with an enriched benthic zone. In P. E. Gibbs (Ed.), Proceedings of 19th EMBS (pp. 97-108). Cambridge: Cambridge University Press.

Fedorov, K. N. (1986). The physical nature and structure of oceanic fronts. Berlin: Springer-Verlag.
Ferrari, R. (2011). A frontal challenge for climate models. Science, 332 316-317. https://doi.org/10.1126/science.1203632

Ferrari, R., \& Nikurashin, M. (2010). Suppression of eddy diffusivity across jets in the Southern Ocean. Journal of Physical Oceanography, 40, 1501-1519. https://doi.org/10.1175/2010JPO4278.1

Finnegan, S., Anderson, S. C., Harnik, P. G., Simpson, C., Tittensor, D. P., Byrnes, J. E., ...Pandolfi, J. M. (2015). Paleontological baselines for evaluating extinction risk in the modern oceans. Science, 348, 567570. https://doi.org/10.1126/science.aaa6635

Fritz, S. A., Schnitzler, J., Eronen, J. T., Hof, C., Bohning-Gaese, K., \& Graham, C. H. (2013). Diversity in time and space: Wanted dead or alive. Trends in Ecology and Evolution, 28, 509-516.

Frontier, S. (1986). Studying fronts as contact ecosystems. Elsevier Oceanography Series, 42, 55-66.

Hickox, R., Belkin, I., Cornillon, P., \& Shan, Z. (2000). Climatology and seasonal variability of ocean fronts in the East China, Yellow and Bohai Seas from satellite SST data. Geophysical Research Letters, 27, 29452948. https://doi.org/10.1029/1999GL011223

Hill,M. O.(1979). TWINSPAN-AFORTRAN program for arranging multivariate data in an ordered two-way table by classification of the individuals and attributes. Ithaca, NY: Section of Ecology and Systematics, Cornell University.

Hill, M. O., \& Šmilauer, P. (2005). TWINSPAN for Windows version 2.3. Huntingdon; Ceske Budejovice. Centre for Ecology and Hydrology \& University of South Bohemia.

Hood, R. R., Abbott, M. R., Huyer, A., \& Kosro, P. M. (1990). Surface patterns in temperature, flow, phytoplankton biomass, and species composition in the coastal transition zone off northern California. Journal of Geophysics Research, 95, 18081-18094. https://doi.org/10.1029/ JC095iC10p18081

Houghton, R. W. (1997). Lagrangian flow at the foot of a shelf-break front using a dye tracer injected into the bottom boundary layer. Geophysical Research Letters, 24, 2035-2038. https://doi. org/10.1029/97GL02000

Houghton, R. W. (2002). Diapycnal flow through a tidal front: A dye tracer study on Georges Bank. Journal of Marine Systems, 37, 31-46. https:// doi.org/10.1016/S0924-7963(02)00194-X

Huang, D., Zhang, T., \& Zhou, F. (2010). Sea-surface temperature fronts in the Yellow and East China Seas from TRMM microwave imager data. Deep Sea Research Part II: Topical Studies in Oceanography, 57, 10171024. https://doi.org/10.1016/j.dsr2.2010.02.003

Jablonski, D., Roy, K., \& Valentine, J. W. (2003). Evolutionary macroecology and the fossil record. In T. M. Blackburn \& K. J. Gaston (Eds.), Macroecology: Concepts and consequences (pp. 368-390). Oxford: Blackwell Publishing.

Johannessen, T., Jansen, E., Flatøy, A., \& Ravelo, A. C. (1994). The relationship between surface water masses, oceanographic fronts and paleoclimatic proxies in surface sediments of the Greenland, Iceland, Norwegian Seas. In R. Zahn, T. F. Pedersen, M. A. Kaminski, \& L. Labeyrie (Eds.), Carbon cycling in the glacial ocean: Constraints on the ocean's role in global change. NATO ASI Series (Series I: Global Environmental Change). Berlin: Springer.

Kark, S. (2013). Ecotones and ecological gradients. In R. Leemans (Ed.), Ecological systems (pp. 147-160). New York: Springer.

Koç Karpuz, N., \& Schrader, H. (1990). Surface sediment diatom distribution and Holocene paleotemperature variations in the Greenland, Iceland and Norwegian Sea. Paleoceanography and Paleoclimatology, 5, 557-580. https://doi.org/10.1029/PA005i004p00557

Koizumi, I. (1989). Holocene pulses of diatom growths in the warm Tsushima Current in the Japan Sea. Diatom Research, 4, 55-68. https://doi.org/10.1080/0269249X.1989.9705052

Li, F., Gao, S., Jia, J., \& Zhao, Y. (2002). Contemporary deposition rates of fine-grained sediment in the Bohai and Yellow Seas. OceanologyEt Limnology Sinica, 33, 364-369. 
Li, J., Hu, B., Dou, Y., Zhao, J., \& Li, G. (2012). Modern sedimentation rate, budget and supply of the muddy deposits in the East China Seas. Geological Review, 58, 745-756.

Liu, D., Liu, L., Di, B., Wang, Y., \& Wang, Y. (2015). Paleoenvironmental analyses of surface sediments from the Bohai Sea, China, using diatoms and silicoflagellates. Marine Micropaleontology, 114, 46-54. https://doi.org/10.1016/j.marmicro.2014.11.002

Longhurst, A. R. (2006). Ecological geography of the sea. New York, NY: Academic Press.

Mann, K. H., \& Lazier, J. R. N. (2006). Dynamics of marine ecosystems. Malden, MA: Blackwell.

Margalef, R. (1997). Our biosphere. In O. Kinne (Ed.), Excellence in ecology (Book 10). Oldendorf/Luhe: International Ecology Institute.

Naimie, C. E., Blain, C. A., \& Lynch, D. R. (2001). Seasonal mean circulation in the Yellow Sea-A model-generated climatology. Continental Shelf Research, 21, 667-695. https://doi.org/10.1016/ S0278-4343(00)00102-3

Olson, D., Hitchcock, G., Mariano, A., Ashjian, C., Peng, G., Nero, R., \& Podesta, G. (1994). Life on the edge: Marine life and fronts. Oceanography, 7, 52-60. https://doi.org/10.5670/oceanog.1994.03

Park, S., \& Chu, P. C. (2006). Thermal and haline fronts in the Yellow/ East China Seas: Surface and subsurface seasonality comparison. Journal of Oceanography, 62, 617-638. https://doi.org/10.1007/ s10872-006-0081-3

Pedersen, F. B. (1994). The oceanographic and biological tidal cycle succession in shallow sea fronts in the North Sea and the English Channel. Estuarine, Coastal and Shelf Science, 38, 249-269. https:// doi.org/10.1006/ecss.1994.1017

Pinchuk, A. I., \& Paul, A. J. (2000). Zooplankton of the Okhotsk Sea: A review of Russian studies (p. AK-SG-00-02.). Fairbanks: University of Alaska Sea Grant.

Ren, J., Gersonde, R., Esper, O., \& Sancetta, C. (2014). Diatom distributions in northern North Pacific surface sediments and their relationship to modern environmental variables. Palaeogeography, Palaeoclimatology, Palaeoecology, 402, 81-103. https://doi. org/10.1016/j.palaeo.2014.03.008

Rijstenbil, J. (1987). Phytoplankton composition of stagnant and tidal ecosystems in relation to salinity, nutrients, light and turbulence. Netherlands Journal of Sea Research, 21, 113-123. https://doi. org/10.1016/0077-7579(87)90027-5

Schrader, H., \& Sorknes, R. (1991). Peruvian coastal upwelling: Late Quaternaryproductivitychangesrevealedbydiatoms.MarineGeology, 97, 233-249. https://doi.org/10.1016/0025-3227(91)90118-N

Shao, H. (2013). Study of dinoflagellate cysts in the surface sediment of the Yellow Sea and Yangtze River mouth (Master thesis). Beijing: Yantai Institute for Coastal Zone Research, Chinese Academy of Sciences.

Smol, J. P., \& Stoermer, E. F. (2010). Applications and uses of diatoms: Prologue. In J. P. Smol \& E. F. Stoermer (Eds.), The diatoms: Applications for the environmental and earth sciences (pp. 3-7). New York, NY: Cambridge University Press.

Sournia, A. (1994). Pelagic biogeography and fronts. Progress in Oceanography, 34, 109-120. https://doi.org/10.1016/0079-6611(94)90004-3

$\mathrm{Su}, \mathrm{J}$. (1998). Circulation dynamics of the China Seas north of $18^{\circ} \mathrm{N}$. In A. R. Robinson \& K. H. Brink (Eds.), The sea (pp. 483-505). New York, NY: Wiley.

ter Braak, C. J. F. (1986). Canonical correspondence analysis: A new eigenvector technique for multivariate direct gradient analysis. Ecology, 67, 1167-1179. https://doi.org/10.2307/1938672

ter Braak, C. J. F., \& Smilauer, P. (2002). Canoco for Windows version 4.5. Wageningen: Biometrics-Plant Research International.

Trimmer, M., Gowen, R. J., \& Stewart, B. M. (2003). Changes in sediment processes across the western Irish Sea front. Estuarine,
Coastal and Shelf Science, 56, 1011-1019. https://doi.org/10.1016/ S0272-7714(02)00312-8

Venables, H., Meredith, M. P., Atkinson, A., \& Ward, P. (2012). Fronts and habitat zones in the Scotia Sea. Deep-Sea Research Part II-Topical Studies in Oceanography, 59-60, 14-24. https://doi.org/10.1016/j. dsr2.2011.08.012

Wang, Y., Liu, D., Di, B., Shi, Y., \& Wang, Y. (2016). Distribution of diatoms and silicoflagellates in surface sediments of the Yellow Sea and offshore from the Changjiang River, China. Chinese Journal of Oceanology and Limnology, 34, 44-58. https://doi.org/10.1007/ s00343-015-4237-0

Woodson, C. B., \& Litvin, S. Y. (2015). Ocean fronts drive marine fishery production and biogeochemical cycling. Proceedings of the National Academy of Sciences USA, 112, 1710-1715. https://doi.org/10.1073/ pnas.1417143112

Wu, H., Shen, J., Zhu, J., Zhang, J., \& Li, L. (2014). Characteristics of the Changjiang plume and its extension along the Jiangsu Coast. Continental Shelf Research, 76, 108-123. https://doi.org/10.1016/j. csr.2014.01.007

Yasuhara, M., Tittensor, D. P., Hillebrand, H., \& Worm, B. (2017). Combining marine macroecology and palaeoecology in understanding biodiversity: Microfossils as a model. Biological Reviews, 92, 199-215. https://doi.org/10.1111/brv.12223

Yuan, D. L., Qiao, F. L., \& Su, J. (2005). Cross-shelf penetrating fronts off the southeast coast of China observed by MODIS. Geophysical Research Letters, 32, L19603. https://doi.org/10.1029/2005GL023815

Zang, Z., Wang, H., Xue, Z., Bi, N., Wu, X., \& Zhang, Y. (2015). Temporal and spatial variability of nearshore fronts in the Yellow Sea and its influence on sediment transport and deposition. Marine Geology Frontiers, 31, 1-10.

Zielinski, U., \& Gersonde, R. (1997). Diatom distribution in Southern Ocean surface sediments (Atlantic sector): Implications for paleoenvironmental reconstructions. Palaeogeography, Palaeoclimatology, Palaeoecology, 129, 213-250. https://doi.org/10.1016/ S0031-0182(96)00130-7

\section{BIOSKETCH}

Dongyan LIU is a Senior Principal Research Scientist at East China Normal University and leads the marine algal ecology group. Her research is focused on understanding the spatial and temporal patterns of population dynamics and how these are affected by environmental processes at different scales.

\section{SUPPORTING INFORMATION}

Additional Supporting Information may be found online in the supporting information tab for this article.

How to cite this article: Liu D, Wang Y, Wang Y, Keesing JK. Ocean fronts construct spatial zonation in microfossil assemblages. Global Ecol Biogeogr. 2018;27:1225-1237. https://doi.org/10.1111/geb.12779 